\title{
Trajectories of aquatic insect functional groups along the resistance/resilience axis when facing water flow changes
}

\author{
Bruno Godoy ${ }^{1}$, Francisco Valente Neto $^{2}$, Luciano Queiroz ${ }^{3}$, Luis Holanda ${ }^{4}$, Fabio Roque $^{2}$, \\ Sara Lodi ${ }^{5}$, and Leandro Oliveira ${ }^{4}$ \\ ${ }^{1} \mathrm{UFPA}$ \\ ${ }^{2}$ Universidade Federal de Mato Grosso do Sul \\ ${ }^{3}$ Universidade de Sao Paulo \\ ${ }^{4}$ Universidade Federal de Goias \\ ${ }^{5}$ Universidade Federal de Goias - Campus Samambaia
}

November 11, 2021

\begin{abstract}
1. Understanding how differences in intensity and frequency of hydrological disturbances affect the resistance and resilience of aquatic organisms is key to manage aquatic systems in a fast-changing world. Organisms' responses to environmental changes can be influenced by different life strategies. Some aquatic organisms have strategies that improve the permanence in aquatic systems, while others use strategies that enhance colonization. 2. Therefore, we carried out a manipulative experiment to understand the resistance/resilience of aquatic insects based on their functional characteristics to hydrological disturbances in streams in the Cerrado hotspot. 3. We placed 200 artificial substrates in five streams and submitted them to changing water flow regimes that differed both in frequency and intensity. Then we observed the response of the aquatic community for 39 days. We used a Hierarchical Bayesian strategy approach to estimate the probabilities of permanence and colonization of each life strategy group (nine groups). 4. We observe that the most intense changes in the water flow tend to affect the permanence of almost all groups. However, this effect was reduced in intensity over time. On the other hand, less frequent disturbances, regardless of intensity, tend to reduce the permanence of most groups of aquatic insects over time. The difference in the effect of disturbance regarding intensity (higher or lower) may be related to a greater dispersal capacity of some groups. 5 . These results are worrisome in a scenario of reduced riparian vegetation around streams and with the expectation of precipitation to become more concentrated in shorter periods of time due to climate change in the Cerrado hotspot. Together, these anthropogenic changes tend to increase the effect of runoff on the lotic systems and, consequently, reduces the permanence of many groups of aquatic insects in their habitat, particularly those with traits associated with permanence.
\end{abstract}

Running head: Aquatic insects and water flow changes

Trajectories of aquatic insect functional groups along the resistance/resilience axis when facing water flow changes

Godoy $\mathrm{BS}^{1^{*}}$, Valente-Neto $\mathrm{F}^{2}$, Queiroz $\mathrm{LL}^{3}$, Holanda $\mathrm{LFR}^{4}$, Roque $\mathrm{FO}^{2,5}$, Lodi $\mathrm{S}^{4}$, Oliveira $\mathrm{LG}^{6}$

1 Program of Aquatic Ecology and Fishery, UFPA, Belém, Brazil

2 Federal University of Mato Grosso do Sul, Campo Grande, MS, Brazil

3 Institute of Biomedical Science, USP, São Paulo, Brazil

4 Program of Ecology and Evolution, UFG, Goiânia, Brazil 
5 Centre for Tropical Environmental and Sustainability Science (TESS), James Cook University, Cairns, Australia

6 Biological Science Institute, UFG, Goiânia, Brazil

* Corresponding author: bspacek@ufpa.br

\section{Abstract}

1. Understanding how differences in intensity and frequency of hydrological disturbances affect the resistance and resilience of aquatic organisms is key to manage aquatic systems in a fast-changing world. Organisms' responses to environmental changes can be influenced by different life strategies. Some aquatic organisms have strategies that improve the permanence in aquatic systems, while others use strategies that enhance colonization.

2. Therefore, we carried out a manipulative experiment to understand the resistance/resilience of aquatic insects based on their functional characteristics to hydrological disturbances in streams in the Cerrado hotspot.

3. We placed 200 artificial substrates in five streams and submitted them to changing water flow regimes that differed both in frequency and intensity. Then we observed the response of the aquatic community for 39 days. We used a Hierarchical Bayesian strategy approach to estimate the probabilities of permanence and colonization of each life strategy group (nine groups).

4. We observe that the most intense changes in the water flow tend to affect the permanence of almost all groups. However, this effect was reduced in intensity over time. On the other hand, less frequent disturbances, regardless of intensity, tend to reduce the permanence of most groups of aquatic insects over time. The difference in the effect of disturbance regarding intensity (higher or lower) may be related to a greater dispersal capacity of some groups.

5. These results are worrisome in a scenario of reduced riparian vegetation around streams and with the expectation of precipitation to become more concentrated in shorter periods of time due to climate change in the Cerrado hotspot. Together, these anthropogenic changes tend to increase the effect of runoff on the lotic systems and, consequently, reduces the permanence of many groups of aquatic insects in their habitat, particularly those with traits associated with permanence.

\section{Key words}

Bayesian inference; Space-state design; Resistance-resilience axis; Hierarchical model; Functional trait; Cerrado streams.

\section{Introduction}

The high rates of change in natural environments direct and indirectly caused by human activities may exert negative effects on terrestrial and aquatic ecosystems (Secretariat of the Convention on Biological Diversity 2020). In lotic environments, human modifications at local (e.g., removal of riparian vegetation), regional (e.g., river dam) and global scales (e.g., climate change) can change water flow, and regularity of flood and flash flood events (Allan 2004, Dudgeon et al. 2006, Poff et al. 2007, IPCC 2014). Changes made to the surroundings of lotic systems, such as the removal of riparian vegetation and the linearization of water courses, reduces the area available for water infiltration, increasing the occurrence of flood and flash flood events (Resh et al. 1988). Furthermore, global climate changes tend to alter the precipitation regime on a global scale (IPCC 2014, Fischer and Knutti 2015, Donat et al. 2016). In tropical regions, precipitation tends to become more concentrated in shorter periods of time, and, consequently, the amounts of heavy precipitation events is expected to increase in the coming years (IPCC 2014, Fischer and Knutti 2015). Then, the flow regime of lotic systems will change due to an expected increase in disturbance events caused by altered precipitation. Despite this general expectation, few studies have experimentally addressed the impact of such changes in the biodiversity of tropical streams. Manipulative experiments are key for understanding the mechanisms behind biodiversity response to environmental changes because, they can separate the effects of different drivers related with the disturbance. 
For a long time aquatic environments have been undergoing hydrological disturbances, and studies addressing this topic are essential to understand ecosystem dynamics and biodiversity patterns (Townsend et al. 1997b, Lake 2000, Melo et al. 2003, Sutherland and Freckleton 2013, Shabarova et al. 2021). Historically, knowledge on the effects of hydrological disturbances on biodiversity (e.g., water withdrawal or flash floods) usually focus on taxonomic measures such as species richness and beta diversity indices (Death 1996, Lake 2000, Melo and Froehlich 2004). However, environmental disturbances can affect species differently depending on their functional traits, which still needs to be further studied for aquatic systems (Menezes et al. 2010). Community functionality is an important component of biodiversity, once function considers not only the identity of organisms, but the physiological, behavioral and/or ecological responses of species to the environment (Verberk et al. 2013).

Traits related to permanence and colonization are important for aquatic communities when facing hydrological disturbances. Permanence and colonization traits can be inserted in the so-called resistance/resilience axis, which is relative to the organism occurrence (Townsend et al. 1997a, Verberk et al. 2013, Sarremejane et al. 2020, Wilkes et al. 2020). Resistance traits, such as morphological adaptations for fixation on substrates and body shape, allow organisms to maintain persistent population sizes when resisting disturbances (Mazzucco et al. 2015). Resilience traits are related to life cycle length such that short life cycles enable faster colonization in newly impacted environments. The relationship between resistance and resilience traits is a trade-off, once organisms that have a high resistance to disturbance tend to present reduced resilience characteristics, whereas organisms with low resistance to disturbance tend to have increased resilience (Kappes et al. 2014, Ferzoco 2019).

Functional traits related to the use of the environment (Wilkes et al. 2020), such as for food acquisition and to avoid competition, also affect community functionality. Hydrological disturbances can affect the relative role that functional traits within the resistance/resilience and environment use axes have on organism distribution. An increased environmental disturbance tends to reduce the importance that environmental drivers and competitive interactions have on the functional diversity of communities in a given environment (Lopez et al. 2016). If environmental requirements become less relevant when environmental disturbance is high, aquatic communities will tend to be structured according to traits related to resistance and resilience. In such circumstances, we can expect organisms with different attributes to have different responses to hydrological disturbances. On the other hand, differences in the intensity and frequency of disturbances would select different traits in the communities, leading to different trajectories in the structure of the communities over time.

Under this perspective, we conducted a manipulative hydrological experiment in streams of the Cerrado hotspot to test whether modifying stream flow alter the rate of occurrence and colonization of aquatic insects with different functional traits. We tested two general hypotheses: i) an increased disturbance intensity would reduce the persistence of organisms in the substrates; and ii) higher disturbance frequency would negatively affect organisms that maximize the permanence in the environments. To test these two hypotheses, we categorized the aquatic insects into nine groups with similar functional traits, both morphological and ecological. For each group we established hypotheses related to the permanence and colonization parameters. We designed an experiment in a space-state design (Pedersen et al. 2011), changing both intensity and frequency of water flow, and evaluated the occurrence of the genera. We also estimated how these changes influenced the probabilities of permanence and colonization of each functional group using a Bayesian model. We showed that the frequency of the disturbance was more relevant in changing the probabilities of persistence and colonization, and that this effect is dependent on the functional group.

\section{Methods}

Study area

The experiment was conducted in five streams at the Pirancajuba River basin, within and near the Silvânia National Forest (FLONA Silvânia). FLONA Silvânia is an environmental conservation unit, located in the eastern region of the state of Goiás, with 486.37 hectares that preserves most of the natural characteristics of 
the Cerrado (ICMBio 2015). The region has a warm and semi-humid tropical climate, strongly characterized by a rainy season in the summer (November to March), and a dry winter season with an average duration of four months (May to September) (Nimer 1972). The experiment was conducted July to September 2010, because the dry season maximizes sampling of aquatic insects in Cerrado streams (Bispo et al. 2004, Bispo and Oliveira 2007).

The five streams have similar water velocity, average depth, and streambed composition, and a prevalence of sand, silt, and small-sized stones. Waterflow was the hydrologic measure with the greatest variation (Coefficient of Variation: 108\%), followed by the width of the channel (CV: 67\%). Average depth and water velocity presented more constant values (Table S1).

\section{Experiment}

\section{Space-state experiment}

We used an experimental design based on the space-state concept. A space-state design follows the dynamics of a variable of interest during a fractioned period of time (Pedersen et al. 2011). A relevant point for this method is that the current condition of the variable is bound to its past condition. Changes in the variable after the beginning of the experiment may be addressed to assess the experimental modifications. The parameters permanence and colonization of the genera were our variables of interest.

We used artificial substrates (AS) with standardized area, weight and volume. Each substrate was composed of washed river pebbles and eight leaves of Tapirira guianensis Aubl. (Anacardiaceae), a common plant in the region, with a standardized leaf area of $25.63 \mathrm{~cm}^{2}$, all packed within a $500 \mathrm{~cm}^{3}(10 \mathrm{~cm} \mathrm{x} 10 \mathrm{~cm} \mathrm{x} 5 \mathrm{~cm})$ rectangular wire mold. The use of AS is efficient for experiments of aquatic insect colonization in Cerrado streams and constitutes a well delimited sample unit (Carvalho and Uieda 2006, Godoy et al. 2016). We used a $0.225 \mathrm{~mm}$ hand sieve when sampling the ASs and fixed the samples in $80 \%$ ethanol. The organisms were identified to the highest possible taxonomic resolution (genus level or family) (Wiggins 1977, TrivinhoStrixino and Strixino 1995, Pes et al. 2005, Manzo 2005, Oliveira 2006, Inês et al. 2007, Merritt et al. 2008, Manzo and Archangelsky 2008).

\section{Immediate effect}

We added two substrates to each stream to test the immediate effect of the disturbance on the communities. After 21 days, we collected an experimental unit and subjected another to a disturbance. The 21-days interval was previously reported as enough for the establishment of a stable aquatic insect community (Landeiro et al. 2010, Godoy et al. 2016). The disturbance was an instantaneous increase in water flow using a water pump from a $60 \mathrm{~cm}$ distance upstream. The increased water flow for this experimental unit was $60 \mathrm{~m}^{3}$.hour ${ }^{-1}$ for 10 minutes. To test the immediate effect, we collected the AS right after the disturbance.

\section{Frequency and intensity effects}

A total of $20 \mathrm{AS}$ was introduced to each stream, arranged in four rows, and five columns. The lines were allocated transversally to the stream, and the distance between each line was at least 200 meters. We randomly distributed the frequency of disturbance to each line (Fig. 1). The frequency of the disturbance (applied in each line separately) was composed of the control, disturbance at every six days (F1), disturbance at 3 days (F2) and random disturbance (F3; i.e., 1 control and 3 treatments per stream).

To test the different intensities of disturbance, we conducted the experiment twice. The first time with an increased water flow intensity of $30 \mathrm{~m}^{3}$.hour ${ }^{-1} 10$ minutes on all AS except the control level. The second time the intensity was $60 \mathrm{~m}^{3} \cdot \mathrm{ha}^{-1}$ for 10 minutes. The first battery of the experiment occurred in July and the second in August. The distance among the ASs remained the same.

\section{Sampling design}

We began to sample the experimental units 23 days from the beginning of the experiment. We removed one control and three treatment AS (F1, F2 and F3) from each stream, also using a hand sieve, and collected a 
total of four experimental units per stream per sampling activity. Other four AS were again removed four days later until the 39th day of the experiment, when the fifth and last AS was removed from each stream. At this stage of the experiment the AS were always collected before applying the disturbance. The experimental units amounted to 200 after the frequency and intensity experiments ( 20 units per stream, 5 streams and 2 experimental batteries).

\section{Functional traits}

We divided the genera of aquatic insects into nine groups of organisms with different life history strategies. These groups were formed by combinations of morphological (body shape and morphological structures for fixation in the substrate) and reproductive (life cycle length and potential number of reproductive cycles) functional traits relevant for the permanence and colonization of insects in streams subject to environmental disturbances (Poff et al. 2006, Verberk et al. 2013, Sarremejane et al. 2020). The body shape of the insects collected during the experiment was divided into depressed and cylindrical bodies. The morphological structures for fixation were divided into present and absent. The life cycle length was separated into organisms with relatively short and long cycles and the potential number of reproductive cycles was divided into low and high. The classification into long, short, low or high for functional traits is relative to the set of aquatic genera species observed in the study, taking into account the total time of the study (39 days). Thus, when referring to a long-life cycle, the implication is that an organism of the group has the potential to survive in the watercourse for the total study period. The same reasoning can be used for the number of potential reproductive cycles.

\section{Data analysis}

The data was analyzed based on self-regressive linear models with two parameters of interest, namely the permanence probability of the taxon in the occurrence of the disturbance $(\psi)$, and the colonization probability in a substrate without previous occurrence of the taxon $(\theta)$. The standard model used has the following structure:

$$
O_{t} \sim \operatorname{Bern}\left(P_{t}\right) \backslash n P_{t}=\theta+O_{t-1} \bullet \psi
$$

where $O_{t}$ was the occurrence of the taxon at timet. This model was modified to fit each stage of the experiment. We used Bayesian inference to adjust the models to the data and to estimate the credibility intervals (CI; 95\%) for the parameters of interest. All analyses were conducted in R (R Development Core Team 2020), using the runjags package (Denwood 2016). We calculated the CI using the methodology of re-sampling by relevance, in a Monte Carlo Markov chain iteration (Gelman et al. 2000, Andrade and Kinas 2008). In all analyses we used 5 parallel chains, burning the first 1000 iterations and sampling every 50 iterations, in a total of 5000 chain steps. The priori distributions of all analysis were not informative.

The combinations of the traits of the insects characterize the life history strategies for the organisms (Poff et al. 2006, Verberk et al. 2013, Sarremejane et al. 2020). We elaborated individual hypotheses for each life history strategy, because many groups of insects had similar traits. The hypotheses are related to estimates of the parameters permanence and colonization and are based on information about how the functional traits may be affected these parameters (Table 1).

\section{Immediate effect}

To test the immediate effect of the disturbance on aquatic insect communities, we estimated the difference between the probabilities of occurrence of each genus before $(B)$ and after $(A)$ the water flow change. For this analysis we used the artificial substrates sampled on day 21 . The model used was:

$$
a_{g}=\frac{b_{g}}{e_{g}} \backslash n B_{i} \sim \operatorname{Bin}\left(b_{g}, n\right) \backslash n A_{i} \sim \operatorname{Bin}\left(a_{g}, n\right) \backslash n b_{g} \sim \operatorname{Beta}(1,1) \backslash n a_{g} \sim \operatorname{Beta}(1,1) \backslash n e_{g} \sim \operatorname{Gamma}(0,0) \backslash n \operatorname{Effect}{ }_{g}=\exp \left(e_{g}\right)
$$


(model 1)

In model $1, B_{i}$ and $A_{i}$ are the number of occurrences of genera $i$ in the streams before and after the disturbance, $n$ was the number of possible events for the occurrence (total observations), and Effect $t_{g}$ was the estimated value for the effect of the disturbance on group $g$.

Probability of permanence and colonization

Using the AS control, we estimated the basal values of the parameters for the permanence and colonization probability for each genus of aquatic insect. The model used in this step was the following modification of the standard model:

$O_{i, t} \sim \operatorname{Bern}\left(P_{i, t}\right) \backslash n P_{i, t}=\theta_{g}+O_{i, t-1} \bullet \psi_{g} \backslash n \theta_{g} \sim \operatorname{Beta}\left(\alpha_{1, g}, \beta_{1, g}\right) \backslash n \psi_{g} \sim \operatorname{Beta}\left(\alpha_{2, g}, \beta_{2, g}\right) \backslash n \alpha_{1, g} \sim \operatorname{Gamma}(0.001,0.001) \backslash$

(model 2)

where $O_{i, t}$ was the occurrence of genus $i$ at time $t, P_{i, t}$ was the probability of the occurrence of genus $i$ at time $t$ given its occurrence at time $t-1$. The parameters $\alpha$ and $\beta$ in model 2 were the priori distribution of the probabilities of permanence $(\psi)$ and colonization $(\theta)$ of group $g$ to which genus $i$ belongs.

Effects of disturbance on the probability of permanence and colonization

After the parameters of permanence and basal colonization of the functional groups were estimated, we used the results of the artificial substrates under different disturbances to assess the effect of water flow changes on genus occurrence. We added a new parameter to the model, which modifies the probability of genera permanence of during the experiment. The model used was:

$$
O_{i, k, t} \sim \operatorname{Bern}\left(P_{i, k, t}\right) \backslash n P_{i, k, t}=\theta_{g}+O_{i, k, t-1} \bullet \psi_{g} \bullet \delta_{k, g} \backslash n \delta_{k, g} \sim N(0,0.001)
$$

(model 3)

where $O_{i, k, t}$ is the occurrence of genus $i$ in treatment $k$ at time $t$. In model $3 \delta_{k, g}$ was the deviation of the probability of permanence of group $g$ from treatment $k$, when compared to the baseline permanence of the group observed in the control $\left(\psi_{g}\right)$. We assumed the six factorial interactions by treatment $\left(\mathrm{I}_{1} \cdot \mathrm{F}_{1}, \mathrm{I}_{1} \cdot \mathrm{F}_{2}\right.$, $\mathrm{I}_{1} \cdot \mathrm{F}_{3}, \mathrm{I}_{2} \cdot \mathrm{F}_{1}, \mathrm{I}_{2} \cdot \mathrm{F}_{2}$ and $\left.\mathrm{I}_{2} \cdot \mathrm{F}_{3}\right)$.

We highlight that the parameters of interest in the study were the hyperparameters estimated in model for $\psi$ and $\theta$. These hyperparameters are calculated using the values for $\alpha$ and $\beta$. Thus, each genus has its estimated probability value; however, all are linked to the baseline values of the functional groups in which they were categorized.

\section{Results}

We collected 15,573 individuals of aquatic insects distributed among 92 taxonomic groups. We identified 84 genera in the orders Coleoptera, Diptera, Ephemeroptera, Plecoptera, Trichoptera and Megaloptera. Eight groups were identified to the family level (Dryopidae, Dystricidae, Gyrinidae, Hydrophilidae, Ptilodactylidae, Ceratopogonidae, Empididae and Simuliidae). The Chironomidae family was the most well represented, with 38 genera, followed by the order Ephemeroptera (20 genera), Trichoptera (13 genera) and Elmidae (10 genera). The order Plecoptera had only the genus Anacroneuria (Perlidae) and we identified the genera Corydalus and Protosialis in the order Megaloptera.

Immediate effect on the occurrence of the functional groups

The two intensities of disturbance had different effects on the occurrence of the functional groups (Fig. 2). The probability of occurrence reduced for all groups after the strongest disturbance (Intensity 2), except for 
organisms with depressed body (group 1). The group of organisms with appendixes to fix in the substrate showed the highest reduction in the probability of occurrence at the highest intensity of the disturbance (group 8). For the weakest disturbance (Intensity 1), only Chironomidae, Baetidae and Trichoptera shelter builders (groups 3, 7 and 9) had a reduced probability of occurrence.

\section{Probability of permanence and basal colonization}

Each functional group showed different permanence probability and basal colonization values (Fig. 3). Only the groups of including Chironomidae and Ceratopogonidae larvae (groups 3 and 4 ) had $\psi$ and $\theta$ estimates supported by hypothesized values. The groups of Empididae and Simullidae larvae (group 5), Baetidade (6), Leptohyphidae, Leptophlebiidae and Plecoptera (7), larvae with anal appendix (8) and shelter-building larvae (9) had their hypotheses partially corroborated, and the value of at least one of the parameters was similar to the hypothesized values.

Coleoptera larvae with depressed body presented a moderate probability of colonization, and a low probability of permanence (Fig. 3A). The genera Macrelmis had the highest estimated probability of colonization (Fig. S1). The probability of colonization for Coleoptera larvae with cylindrical body was estimated between 0.15 and 0.29 (Fig. 3B), and the genera Heterelmis, Neoelmis and the family Ptilodactylidae had the highest probability of colonization and permanence among the coleoptera (Fig. S2).

The group of Chironomidae larvae had the most variable probability of colonization, with values ranging from 0.12 to 0.86 (Fig. 3C). The genera Rheotanytarsus presented the highest probabilities of both colonization and permanence. On the other hand, the generaPolypedilum presented a low probability of colonization, and a high permanence. The genera Cryptochironomus ,Stempellinela, Stenochironomus and Zavrellielapresented the opposite pattern, with high probability of colonization and low permanence (Fig. S3). Ceratopogonidae larvae presented a high colonization rate and low permanence rate, typical of R-strategist groups (Fig. 3D and Fig. S4). Empididae and Simuliidae larvae showed lower colonization rates compared to Ceratopogonidae, but a higher permanence probability (Fig. 3E and Fig. S5).

In the absence of disturbance, the colonization probability of fusiform Ephemeroptera nymphs ranged from 0.26 to 0.38 and permanence probabilities were greater than 0.4 (Fig. 3F and Fig. S6). The insects with depressed bodies showed a highly variable colonization rate (Fig. 3G). Tricorythopsis and Simothraulopsis showed the lowest colonization probabilities, while Leptohyphes, Tricorythodes and Anacroneuria showed high colonization probabilities, ranging from 0.45 to 0.54 (Fig. S7). The probability of colonization was low for larvae with anal claws (Fig. $3 \mathrm{H}$ ), and the probability of permanence for this group ranged between 0.18 and 0.28 , with the lowest value for Macronema, and the highest for Corydalus (Fig. S8). The colonization probabilities of shelter-building Trichoptera ranged from 0.19 to 0.36 (Fig. 3I), with the lowest value for Oecetis and the highest for Neotrichia. The probabilities of permanence for this group (shelter-building Trichoptera) were lower than 0.20 , except for the genera Neotrichia and Oecetis, with probabilities of 0.28 and 0.31 , respectively (Fig. S9).

\section{Long-term effects on the probability of permanence for the functional groups}

In general, disturbance intensity affected similarly the permanence probabilities of the functional groups (Table S2). However, the frequency of disturbance events affected the permanence probability of all groups except Chironomidae larvae (group 3). The lower frequency of disturbance events (F1: disturbance every 6 days) affected a greater number of groups when compared to the higher frequency (F2: disturbance every 3 days) or to the random frequency treatments (F3). The lower frequency reduced the permanence probabilities more strongly (Fig. 4).

The probability of permanence for Diptera was little affected by the disturbances. Group 3 (Chironomidae) was not affected by the treatments (Fig. 4C) and group 4 (Ceratopogonidae) was affected only by treatment 1 (low intensity and lower frequency, Fig. 4D). Depressed-bodied Coleoptera were less affected than those with cylindrical bodies (group 1 and 2, respectively), for example, Baetidae nymphs (group 6, Fig 4F) were more affected than flat-bodied insects (group 7, Fig 4G). In addition, larvae with anal claws (group 8, Fig 4H) 
were less affected by disturbance than Trichoptera building portable shelters (group 9, Fig 4I). Unexpectedly, the permanence probability of group 5, represented by the families Empididae and Simuliidae (Diptera), was affected by all treatments in the experiment (Fig 4E).

\section{Discussion}

The increase of hydrological disturbances is expected to impact aquatic biodiversity worldwide in the coming years (IPCC 2014, Fischer and Knutti 2015). Previous studies have shown that high water flow intensity and frequency can drive rapid declines in species richness and abundance of aquatic biodiversity (Resh et al. 1988, Melo et al. 2003). However, functional responses of tropical biodiversity, particularly aquatic insects, remains poorly understood. Here, we showed different responses of aquatic insect to changes in the water flow frequency and intensity in streams of the Cerrado biome, a biodiversity hotspot expected to experience strong hydrological changes related to land use and climate change (Bowman 2016). In general, we observed that a greater water flow intensity tends to affect the permanence of almost all insect groups; however, this effect is softened over time. On the other hand, less frequent disturbances, regardless of intensity, tend to reduce the permanence of most groups of aquatic insects over time.

Our study adds evidence that a generalization like "water flow intensity affected the permanence of..." is valid mainly for the period immediately after the disturbance, because the effects of disturbance lose its intensity over time on macroinvertebrates. This pattern may be related to the colonization capacity of macroinvertebrates, since many recolonize substrates subject to disturbances in few hours or days (Townsend and Hildrew 1976, Brooks and Boulton 1991, Landeiro et al. 2010, Godoy et al. 2016). In addition, Poff \& Zimmerman (2010) reviewed the response of aquatic organisms to changes in water flow and showed that the abundance and diversity of macroinvertebrates have mixed responses to changes in intensity of the flow regime. We did not assess the abundance and diversity of aquatic insects. Still, our results also indicate that the occurrence of insects in relation to disturbance intensity depends on time elapsed (immediately or days after the disturbance).

Frequency affected the permanence in an opposite direction than we had hypothesized (second hypothesis) based on classical studies on disturbance in aquatic systems (Connell 1978, Resh et al. 1988, Ward 1989, Townsend et al. 1997b). Most groups that showed this reduced permanence when under less frequent disturbances (depressed bodied beetles, cylindrical beetles, Ceratopogonidae, depressed body insects, larvae with anal claws and shelter-building Trichoptera, Figure 4A, B, D, G, H and I) had, in general, a greater baseline probability of colonization than of permanence. The combination of these results shows that the effect of disturbance frequency does not imprint a general pattern in all groups, but rather depends on the functional characteristics of the organisms.

Disturbance may be an external element that reduces the effects of interactions between the organisms inhabiting the artificial substrates (Menge and Sutherland 1987). With a higher frequency of disturbances, habitats become more susceptible to colonization, because frequent disturbances remove organisms from artificial substrates (Burton et al. 2020), loosening competition. In this scenario, groups with selected characteristics that favor displacement and colonization in detriment of mechanisms of resistance to disturbances may quickly colonize open-habitats, or even increase their population sizes in a short period of time (e.g., Chironomidae), thus increasing the likelihood of groups permanence. On the other hand, less frequent disturbances can favor populations with high growth rates, increasing the effect of intraspecific competition (Huston 1979, Magurran and Huston 1995). This may explain, for example, moderate probabilities of colonization and permanence to Empididae and Simulidae, groups with strategies to remain fixed on the stream substrate and fast life cycle (Carvalho and Uieda 2004, 2006, Landeiro et al. 2010). Such reasoning is congruent with part of the assumptions of the intermediate disturbance hypothesis, in which the frequency of disturbances is directly related to the relaxation of interactions among species (Wilkinson 1999).

The power of the Bayesian model to detect the response of different functional groups

The individual hypothesis for colonization and permanence of functional groups using the space-state Bayesian model yielded at least three different response patterns: i) the estimated parameters of permanence and 
colonization confirm the hypothesis raised; ii) at least one of the parameters confirm our hypothesis; or iii) no parameter fit the hypothesis.

The Chironomidae and the Ceratopogonidae larvae are clear examples of the first case. Their probabilities of permanence and colonization were very close to the hypothesized probabilities. During the experiment we found a low probability of permanence, but a high and moderate probability of colonization for Chironomidae and Ceratopogonidae, respectively. This indicates that these organisms invest primarily in a rapid re-colonization of habitats, which is in line with the life cycle of these organisms. The representatives of these families usually have high densities and a relatively short life cycle (Trivinho-Strixino and Strixino 1999). The life span of Ceratopogonidade and Chironomidae females can reach 70 and 22 days, respectively (Braverman 1994), period during which the females have two to four reproductive cycles (Corbi and Trivinho-Strixino 2006).

Only the parameters estimated for the group composed by Coleoptera larvae with depressed bodies (e.g., Macrelmis , Phanocerus, Xenelmis ) did not support our hypotheses. Contrary to our expectation, these larvae had a low permanence during the study period accompanied by a moderate habitat colonization capacity. An explanation for this pattern may be the mobility capacity of these larvae, and their active search for habitats (Carvalho and Uieda 2006) that allows an alternated occurrence of these organisms in the samples.

Our hypotheses were supported by at least one of the estimated parameters of the remaining six groups. Many explanations may account for these results, and we need highlight that some parameters may have been overestimated in some hypotheses because we had limited previous information about the biology of some groups. Despite this Hutchinsonian shortfall, mobility of Coleoptera larvae, other uses to shelters (e.g., Trichoptera using the shelter to protect against possible natural enemies, Morse 2009), rapid colonization in empty habitat (Ephemeroptera and Plecoptera, Carvalho and Uieda 2004, 2006, Landeiro et al. 2010), and the use of drift strategies for colonization (Megaloptera and some Coleoptera and Trichoptera larvae, Krueger and Cook 1984, Townsend and Hildrew 1994, Godoy et al. 2016) may explain the divergence between the hypothesis and patterns observed in this study.

A relevant point in our study was the way we used the functional groups. The groups were assembled according to life strategies based on functional traits. In addition, we established testable numerical hypotheses for predetermined parameters. Both biology of organisms and ecological theory were included in a predictive way (Verberk et al. 2013). The elaboration of these hypotheses and our experimental design in space-state made it possible for us to measure the permanence and colonization responses separately. The separate estimation of the parameters that represent these functional responses was essential to understand how changes in flow conditions can impact the occurrence of organisms. We also directly tested the axes of resistance and resilience that summarize the fundamental theoretical functional traits of aquatic insects undergoing disturbances in the environment (Lopez et al. 2016). Separately, functional groups respond differently to changes in the flow regimes, even for groups with similar baseline permanence and colonization values.

Understanding the response of functional groups to different disturbances is an important tool to elaborate theories and hypotheses that explain temporal dynamics of aquatic communities, and to describe the possible alternative states presented by communities depending on environmental stress. Despite the separate estimates of probability of permanence and colonization, the experimental design does not allow the total separation between these two parameters and, thus, the estimated parameters may have some level of covariance. The long-term permanence probability may be the result of a continuous occupation of organisms, partially affected by colonization processes. Despite this limitation, the use of a space-state analysis reduces this covariance to acceptable limits. To control and quantify this covariance, a similar study limiting the habitat colonization is necessary. It is also noteworthy that our experimental design was based on a categorical quantification of the disturbances, leaving out a possible continuum for flow disturbance intensity and frequency. However, this qualification is common in studies that assess the effect of the disturbance on biodiversity (Poff and Zimmerman 2010) and the levels we choose have relevance to the type of environment we test our hypotheses. 


\section{Implication of our findings for aquatic biodiversity conservation in the Cerrado Hotspot}

Cerrado streams usually undergo seasonal flooding, and the variation in water flow usually is not drastic especially in headwater streams (Bispo et al. 2004, Bispo and Oliveira 2007). The results of our study draw attention to biodiversity conservation. Processes of land modification near streams is accelerating in the Cerrado region (Bowman 2016). The loss of riparian forest makes flooding events more frequent, especially in the rainy season. Cerrado is also targeted for construction of small to medium sized dams, which directly affects the hydrological dynamics of lotic systems. We detected that a reduced permanence of groups compared to natural conditions due to disturbance frequency, and there is a possibility of biodiversity losses.

Climate change is predicted to condense the rainy season into shorter periods of time at a regional scale, but with more intense precipitation events in the tropics (IPCC 2014, Fischer and Knutti 2015). Thus, on a broader temporal and spatial scale, we would have more accentuated and more frequent rains, which will directly affect the permanence of aquatic insects in headwater streams, especially those with less vegetation cover. Therefore, maintaining the riparian forest cover becomes key in maintaining the biodiversity of aquatic entomofauna (Dala-Corte et al. 2020), as it prevents water runoff from reaching streams quickly, attenuating flow disturbances and losses of functional groups important to these aquatic insect communities.'

\section{Acknowledgments}

We thank Merlin $M$ for the drawings; Capes for the scholarship of Valente-Neto $F$ (process: 88882.317337/2019-01); CNPq for the scholarship of Holanda LFR; the ECOEVOL program; Mazão GR for help in identifying the material; Araújo CSC, Fernandes AS, Araújo WS and Dias AC for help in the field; and the management of FLONA de Silvania; FOR was supported by grants from Conselho Nacional de Desenvolvimento Científico e Tecnológico (CNPq) and Fundação de Apoio ao Desenvolvimento do Ensino, Ciência e Tecnologia do Estado de Mato Grosso do Sul (FUNDECT).

\section{Author contributions}

Godoy BS and Holanda LFR conceived the ideas, designed methodology; Holanda LFR and Queiroz LL collected the data; Godoy BS analyzed the data; Godoy BS, Queiroz LL and Valente-Neto F wrote the original manuscript. Roque FO, Lodi S and Oliveira LG revised the final manuscript. All authors contributed critically to the drafts and gave final approval for publication.

\section{References}

Allan, J. D. 2004. Landscapes and Riverscapes: The Influence of Land Use on Stream Ecosystems. Annual Review of Ecology, Evolution, and Systematics 35:257-284.

Andrade, H. A., and P. G. Kinas. 2008. Inferência em ecologia. Atlântica 30:147-160.

Bispo, P. C. P., and L. L. G. Oliveira. 2007. Diversity and structure of Ephemeroptera, Plecoptera and Trichoptera (Insecta) assemblages from riffles in mountain streams of Central Brazil. Revista Brasileira de Zoologia 24:283-293.

Bispo, P., L. Oliveira, V. Crisci-Bispo, and K. Sousa. 2004. Environmental Factors Influencing Distribution and Abundance of Trichopteran Larvae in Central Brazilian Mountain Streams. Studies on Neotropical Fauna and Environment 39:233-237.

Bowman, M. S. 2016. Impact of foot-and-mouth disease status on deforestation in Brazilian Amazon and cerrado municipalities between 2000 and 2010. Journal of Environmental Economics and Management 75:2540.

Braverman, Y. 1994. Nematocera (ceratopogonidae, psychodidae, simuliidae and culicidae) and control methods. Revue Scientifique et Technique de l'OIE 13:1175-1199. 
Brooks, S., and A. Boulton. 1991. Recolonization dynamics of benthic macroinvertebrates after artificial and natural disturbances in an Australian temporary stream. Marine and Freshwater Research 42:295.

Burton, P. J., A. Jentsch, and L. R. Walker. 2020. The Ecology of Disturbance Interactions. BioScience 70:854-870.

Carvalho, E. M., and V. S. Uieda. 2004. Colonization by benthic macroinvertebrates in artificial and natural substrates in a mountain stream from Itatinga, São Paulo, Brazil. Revista Brasileira de Zoologia 21:287-293.

Carvalho, E. M., and V. S. Uieda. 2006. Colonization routes of benthic macroinvertebrates in a stream in southeast Brazil. Acta Limnologica Brasiliensia 18:367-376.

Connell, J. H. 1978. Diversity in Tropical Rain Forests and Coral Reefs. Science 199:1302-1310.

Corbi, J. J., and S. Trivinho-Strixino. 2006. Ciclo de vida de duas espécies de Goeldichironomus (Diptera, Chironomidae). Revista Brasileira de Entomologia 50:72-75.

Dala-Corte, R. B., A. S. Melo, T. Siqueira, L. M. Bini, R. T. Martins, A. M. Cunico, A. M. Pes, A. L. B. B. Magalhaes, B. S. Godoy, C. G. Leal, C. S. Monteiro-Junior, C. Stenert, D. M. P. P. Castro, D. R. Macedo, D. P. Lima-Junior, E. A. Gubiani, F. C. Massariol, F. B. Teresa, F. G. Becker, F. N. Souza, F. Valente-Neto, F. L. Souza, F. F. Salles, G. L. Brejao, J. G. Brito, J. R. S. S. Vitule, J. Simiao-Ferreira, K. Dias-Silva, L. Albuquerque, L. Juen, L. Maltchik, L. Casatti, L. Montag, M. E. Rodrigues, M. Callisto, M. A. M. M. Nogueira, M. R. Santos, N. Hamada, P. A. Z. Z. Pamplin, P. S. Pompeu, R. P. Leitao, R. Ruaro, R. Mariano, S. R. M. M. Couceiro, V. Abilhoa, V. C. Oliveira, Y. Shimano, Y. Moretto, Y. R. Suarez, and F. de O. Roque. 2020. Thresholds of freshwater biodiversity in response to riparian vegetation loss in the Neotropical region. Journal of Applied Ecology 57:1391-1402.

Death, R. G. 1996. The effect of patch disturbance on stream invertebrate community structure: the influence of disturbance history. Oecologia 108:567-576.

Denwood, M. J. 2016. runjags : An R Package Providing Interface Utilities, Model Templates, Parallel Computing Methods and Additional Distributions for MCMC Models in JAGS. Journal of Statistical Software 71.

Donat, M. G., A. L. Lowry, L. V. Alexander, P. A. O'Gorman, and N. Maher. 2016. More extreme precipitation in the world's dry and wet regions. Nature Climate Change 6:508-513.

Dudgeon, D., A. H. Arthington, M. O. Gessner, Z.-I. Kawabata, D. J. Knowler, C. Leveque, R. J. Naiman, A.H. Prieur-Richard, D. Soto, M. L. J. Stiassny, and C. A. Sullivan. 2006. Freshwater biodiversity: importance, threats, status and conservation challenges. Biological Reviews 81:163.

Ferzoco, I. M. C. 2019. Testing Trade-Offs in Dispersal and Competition in a Guild of Semi-Aquatic Backswimmers. University of Toronto.

Fischer, E. M., and R. Knutti. 2015. Anthropogenic contribution to global occurrence of heavy-precipitation and high-temperature extremes. Nature Climate Change 5:560-564.

Gelman, A., C. J.B., S. H.S, D. B. D. Rubin, J. Carlin, H. Stern, and D. B. D. Rubin. 2000. Bayesian data analysis. Page Vasa. Chapman \& Hall, London.

Godoy, B. S., L. L. Queiroz, S. Lodi, J. D. Nascimento de Jesus, and L. G. Oliveira. 2016. Successional colonization of temporary streams: An experimental approach using aquatic insects. Acta Oecologica 77:4349.

Huston, M. 1979. A General Hypothesis of Species Diversity. The American Naturalist 113:81-101.

ICMBio. 2015. Plano de manejo da Floresta Nacional de Silvania. First edition. Brasilia. 
Ines, M., S. Passos, J. L. Nessimian, and N. F. Junior. 2007. Chaves para identificacao dos generos de Elmidae (Coleoptera) ocorrentes no Estado do Rio de Janeiro, Brasil. Revista Brasileira de Entomologia $51: 42-53$.

IPCC. 2014. Climate Change 2014: Synthesis Report. Contribution of Working Groups I, II and III to the Fifth Assessment Report of the Intergovernmental Panel on Climate Change. Page Ipcc.

Kappes, H., O. Tackenberg, and P. Haase. 2014. Differences in dispersal- and colonization-related traits between taxa from the freshwater and the terrestrial realm. Aquatic Ecology 48:73-83.

Krueger, C. C., and E. F. Cook. 1984. Life cycles, standing stocks, and drift of some Megaloptera, Ephemeroptera, and Diptera from streams in Minnesota, U.S.A. Aquatic Insects 6:101-108.

Lake, P. S. 2000. Disturbance, patchiness, and diversity in streams. Journal of the North American Benthological Society 19:573-592.

Landeiro, V. L., N. Hamada, B. S. Godoy, and A. S. Melo. 2010. Effects of litter patch area on macroinvertebrate assemblage structure and leaf breakdown in Central Amazonian streams. Hydrobiologia 649:355-363.

Lopez, B., K. Burgio, M. Carlucci, K. Palmquist, A. Parada, V. Weinberger, and A. Hurlbert. 2016. A new framework for inferring community assembly processes using phylogenetic information, relevant traits and environmental gradients. One Ecosystem 1:e9501.

Magurran, A. E., and M. A. Huston. 1995. Biological Diversity: The Coexistence of Species on Changing Landscapes. The Journal of Applied Ecology 32:668.

Manzo, V. 2005. Key to the South America genera of Elmidae (Insecta: Coleoptera) with distributional data. Studies on Neotropical Fauna and Environment 40:201-208.

Manzo, V., and M. Archangelsky. 2008. A key to the known larvae of South American Elmidae (Coleoptera: Byrrhoidea), with a description of the mature larva of Macrelmis saltensis Manzo. Annales de Limnologie International Journal of Limnology 44:63-74.

Mazzucco, R., T. Van Nguyen, D.-H. Kim, T.-S. Chon, and U. Dieckmann. 2015. Adaptation of aquatic insects to the current flow in streams. Ecological Modelling 309-310:143-152.

Melo, A. S., and C. G. Froehlich. 2004. Colonization by Macroinvertebrates of Experimentally Disturbed Stones in Three Tropical Streams Differing in Size. International Review of Hydrobiology 89:317-325.

Melo, A. S., D. K. Niyogi, C. D. Matthaei, and C. R. Townsend. 2003. Resistance, resilience, and patchiness of invertebrate assemblages in native tussock and pasture streams in New Zealand after a hydrological disturbance. Canadian Journal of Fisheries and Aquatic Sciences 60:731-739.

Menezes, S., D. J. Baird, and A. M. V. M. Soares. 2010. Beyond taxonomy: a review of macroinvertebrate trait-based community descriptors as tools for freshwater biomonitoring. Journal of Applied Ecology 47:711719 .

Menge, B. A., and J. P. Sutherland. 1987. Community Regulation: Variation in Disturbance, Competition, and Predation in Relation to Environmental Stress and Recruitment. The American Naturalist 130:730-757.

Merritt, R. W., K. W. Cummins, and M. B. Berg. 2008. An introduction to the aquatic insects of North America. Fourth edition. Kendall / Hunt Publishing Company, Dubuque.

Morse, J. C. 2009. Trichoptera (Caddisflies). Pages 1015-1020 Encyclopedia of Insects. Elsevier.

Nimer, E. 1972. Climatologia da Regiao Centro-Oeste do Brasil Introducao a Climatologia Dinamica. Revista Brasileira de Geografia 34:3-30.

Oliveira, L. G. 2006. Trichoptera. Page in C. Costa, S. Ide, and C. Simonka, editors. Insetos imaturos Metamorfose e identificacao. First edition. Holos, Ribeirao Preto. 
Pedersen, M. W., C. W. Berg, U. H. Thygesen, A. Nielsen, and H. Madsen. 2011. Estimation methods for nonlinear state-space models in ecology. Ecological Modelling 222:1394-1400.

Pes, A. M. O., N. Hamada, and J. L. Nessimian. 2005. Chaves de identificacao de larvas para familias e generos de Trichoptera (Insecta) da Amazonia Central, Brasil. Revista Brasileira de Entomologia 49:181-204.

Poff, N. L., J. D. Olden, D. M. Merritt, and D. M. Pepin. 2007. Homogenization of regional river dynamics by dams and global biodiversity implications. Proceedings of the National Academy of Sciences 104:5732-5737.

Poff, N. L. R., J. D. Olden, N. K. M. Vieira, D. S. Finn, M. P. Simmons, and B. C. Kondratieff. 2006. Functional trait niches of North American lotic insects: Traits-based ecological applications in light of phylogenetic relationships. Journal of the North American Benthological Society 25:730-755.

Poff, N. L., and J. K. H. Zimmerman. 2010. Ecological responses to altered flow regimes: a literature review to inform the science and management of environmental flows. Freshwater Biology 55:194-205.

R Development Core Team. 2020. R Development Core Team, R: a language and environment for statistical computing. Page R: A Language and Environmental for Estatistical Computing.

Resh, V. H., A. V. Brown, A. P. Covich, M. E. Gurtz, H. W. Li, G. W. Minshall, S. R. Reice, A. L. Sheldon, J. B. Wallace, and R. C. Wissmar. 1988. The Role of Disturbance in Stream Ecology. Journal of the North American Benthological Society 7:433-455.

Sarremejane, R., N. Cid, T. Datry, R. Stubbington, M. Alp, M. Canedo-Arguelles, A. Cordero-Rivera, Z. Csabai, C. Gutierrez-Canovas, J. Heino, M. Forcellini, A. Millan, A. Paillex, P. Pařil, M. Polášek, J. M. T. de Figueroa, P. Usseglio-Polatera, C. Zamora-Muñoz, and N. Bonada. 2020. DISPERSE: A trait database to assess the dispersal potential of aquatic macroinvertebrates. Scientific Data 7:386.

Secretariat of the Convention on Biological Diversity. 2020. Global Biodiversity Outlook 5. Montreal.

Shabarova, T., M. M. Salcher, P. Porcal, P. Znachor, J. Nedoma, H.-P. Grossart, J. Sed̆a, J. Hejzlar, and K. Šimek. 2021. Recovery of freshwater microbial communities after extreme rain events is mediated by cyclic succession. Nature Microbiology.

Sutherland, W., and R. Freckleton. 2013. Identification of 100 fundamental ecological questions. Journal of Ecology 2013:58-67.

Townsend, C., S. Dolédec, and M. Scarsbrook. 1997a. Species traits in relation to temporal and spatial heterogeneity in streams: a test of habitat templet theory. Freshwater Biology 37:367-387.

Townsend, C. R. C., and A. G. A. Hildrew. 1994. Species traits in relation to a habitat templet for river systems. Freshwater Biology 31:265-275.

Townsend, C. R., and A. G. Hildrew. 1976. Field Experiments on the Drifting, Colonization and Continuous Redistribution of Stream Benthos. The Journal of Animal Ecology 45:759.

Townsend, C. R., M. R. Scarsbrook, S. Dolèdec, and S. Dolédec. 1997b. The intermediate disturbance hypothesis, refugia, and biodiversity in streams. Limnology and Oceanography 42:938-949.

Trivinho-Strixino, S., and G. Strixino. 1995. Larvas de Chironomidae (Diptera) do Estado de São Paulo: Guia de Identificação e Diagnose dos Gêneros. PPG, ERN, UFSCar, São Carlos.

Trivinho-Strixino, S., and G. Strixino. 1999. Insetos dípteros: quironomídeos. Pages 141-148 in D. Ismael, editor. Biodiversidade do Estado de São Paulo: Invertebrados de água doce. FAPESP, São Paulo.

Verberk, W. C. E. P., C. G. E. van Noordwijk, and A. G. Hildrew. 2013. Delivering on a promise: integrating species traits to transform descriptive community ecology into a predictive science. Freshwater Science $32: 531-547$. 
Ward, J. V. 1989. The four-dimensional nature of lotic ecosystems. Journal of the North American Benthological Society 8:2-8.

Wiggins, G. B. 1977. Larvae of the North American caddisfly genera (Trichoptera). University of Toronto Press, Toronto.

Wilkes, M. A., F. Edwards, J. I. Jones, J. F. Murphy, J. England, N. Friberg, D. Hering, N. L. Poff, P. Usseglio-Polatera, W. C. E. P. Verberk, J. Webb, and L. E. Brown. 2020. Trait-based ecology at large scales: Assessing functional trait correlations, phylogenetic constraints and spatial variability using open data. Global Change Biology 26:7255-7267.

Wilkinson, D. M. 1999. The Disturbing History of Intermediate Disturbance. Oikos 84:145.

\section{Tables}

Table 1. Classification of the genera of aquatic insects according to groups of functional traits and life history strategy when subjected to disturbance events.

\begin{tabular}{|c|c|c|c|c|}
\hline Group & Functional traits & $\begin{array}{l}\text { Life history } \\
\text { strategy }\end{array}$ & Hypothesis & Organisms \\
\hline 1 & $\begin{array}{l}\text { Depressed body; } \\
\text { Relatively long-life } \\
\text { cycle; Low potential } \\
\text { number of } \\
\text { reproductive cycles; } \\
\text { No developed } \\
\text { fixation structure. }\end{array}$ & $\begin{array}{l}\text { Body shape acts as } \\
\text { a resistance factor } \\
\text { against the } \\
\text { disturbance. }\end{array}$ & $\psi$ high $\theta$ low & $\begin{array}{l}\text { Coleoptera larvae } \\
\text { with depressed body }\end{array}$ \\
\hline 2 & $\begin{array}{l}\text { Cylindrical body; } \\
\text { Relatively long-life } \\
\text { cycle; Low potential } \\
\text { number of } \\
\text { reproductive cycles; } \\
\text { No developed } \\
\text { fixation structure. }\end{array}$ & $\begin{array}{l}\text { Body shape does } \\
\text { not confer resistance } \\
\text { to the disturbance. }\end{array}$ & $\psi$ low $\theta$ low & $\begin{array}{l}\text { Coleoptera larvae } \\
\text { with cylindrical } \\
\text { body }\end{array}$ \\
\hline 3 & $\begin{array}{l}\text { Cylindrical body; } \\
\text { Relatively short life } \\
\text { cycle; High } \\
\text { potential number of } \\
\text { reproductive cycles; } \\
\text { No developed } \\
\text { fixation structure. }\end{array}$ & $\begin{array}{l}\text { Life cycle as a } \\
\text { resilience factor. }\end{array}$ & $\psi$ low $\theta$ high & $\begin{array}{l}\text { Chironomidae } \\
\text { larvae }\end{array}$ \\
\hline 4 & $\begin{array}{l}\text { Cylindrical body; } \\
\text { Relatively short life } \\
\text { cycle; Moderate } \\
\text { potential number of } \\
\text { reproductive cycles; } \\
\text { No developed } \\
\text { fixation structure. }\end{array}$ & $\begin{array}{l}\text { Life cycle as a } \\
\text { resilience factor. }\end{array}$ & $\psi$ low $\theta$ moderate & $\begin{array}{l}\text { Ceratopogonidae } \\
\text { larvae }\end{array}$ \\
\hline
\end{tabular}




\section{Figure captions}

Figure 1. Experimental design of the artificial substrates placed within in the streams. A total of five substrates (AS) were placed in four rows transversal to the stream. The frequency of the disturbance (control, F1, F2 or F3) was assigned randomly to each row of each stream. An entire column was randomly selected to be sampled at each sampling procedure. The same design was used for the two times the experiment was conducted, with different intensities of disturbance.

Figure 2: Immediate effect of the disturbance on the permanence probability of the functional groups. Effect is the parameter estimated in the model that affects the probability of occurrence.

Figure 3: Probability density function (PDF) of permanence $(\psi-$ blue $)$ and colonization parameters $(\theta-$ red) for functional groups of aquatic insects, during 39 days in streams of the Brazilian Cerrado. The letters A I correspond to the functional groups of 1 - 9 (A = Depressed body Coleoptera; $\mathrm{B}=$ Cylindrical Coleoptera; $\mathrm{C}=$ Chironomidae; $\mathrm{D}=$ Ceratopogonidae; $\mathrm{E}=$ Empididae and Simuliidae; $\mathrm{F}=$ Baetidae; $\mathrm{G}=\mathrm{Depressed}$ body insects; $\mathrm{H}=$ Larvae with anal claws; and $\mathrm{I}=$ Tricoptera shelter builders). 
Figure 4. Effects of experimental treatments (disturbance intensity and frequency) on the probability of permanence, with the mean values and credible intervals (95\%). $\mathrm{A}=$ Depressed-bodied Coleoptera; $\mathrm{B}=$ Cylindrical Coleoptera; $\mathrm{C}=$ Chironomidae; $\mathrm{D}=$ Ceratopogonidae; $\mathrm{E}=$ Empididae and Simuliidae; $\mathrm{F}=$ Baetidae; $\mathrm{G}=$ Depressed-bodied insects; $\mathrm{H}=$ Larvae with anal claws; and $\mathrm{I}=$ Trichoptera shelter builders. $\mathrm{C}=$ control; F1, F2, and F3=frequency of disturbance (interval in days of 6,3 , and random). The gray band corresponds to the credibility interval of the control.

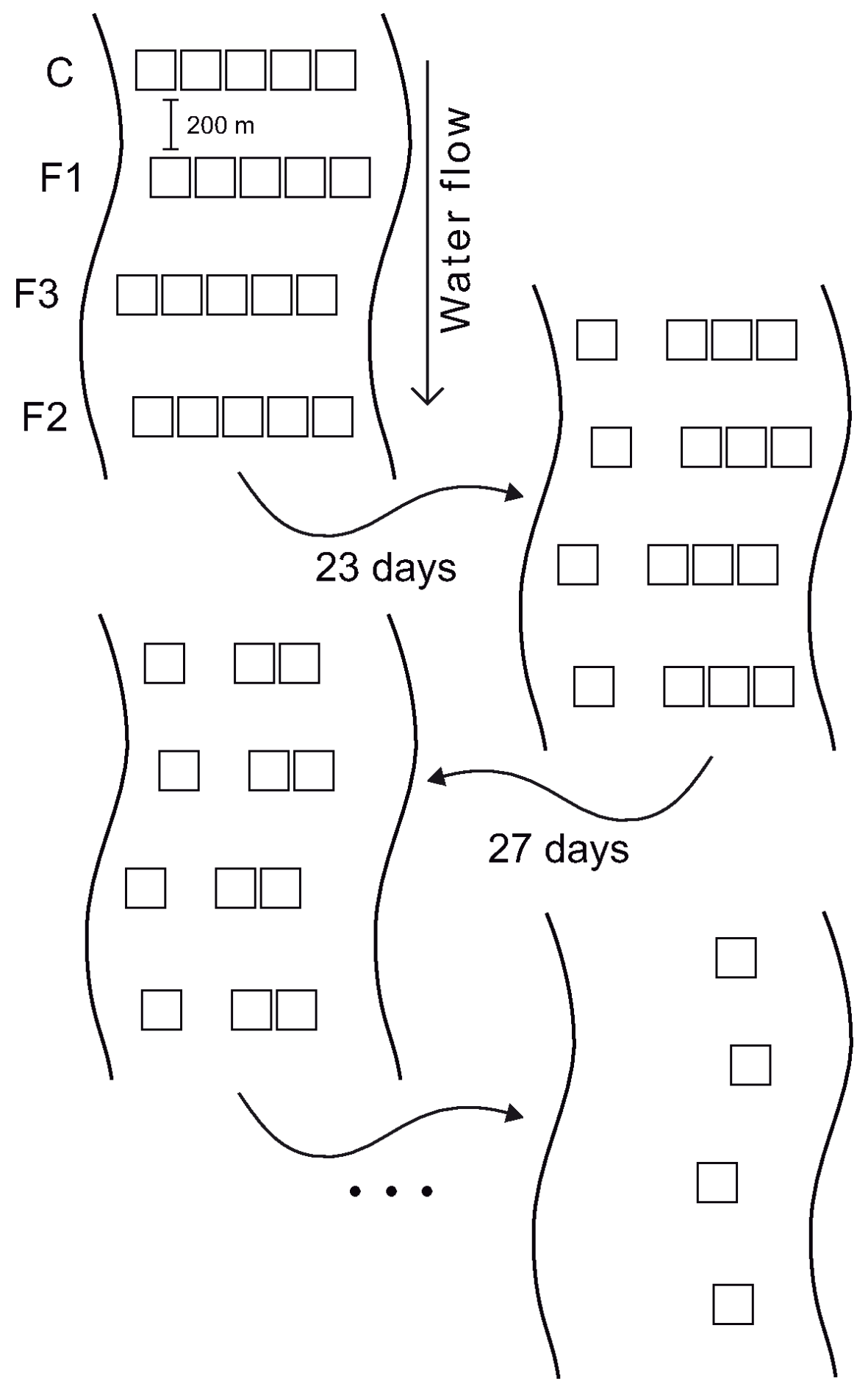


Intensity 1

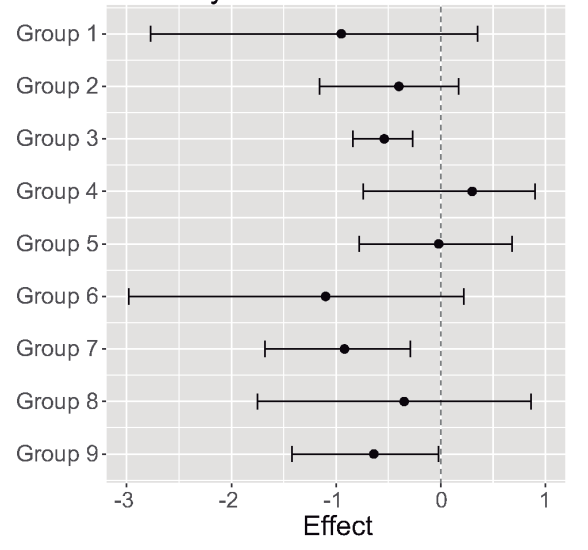

Intensity 2

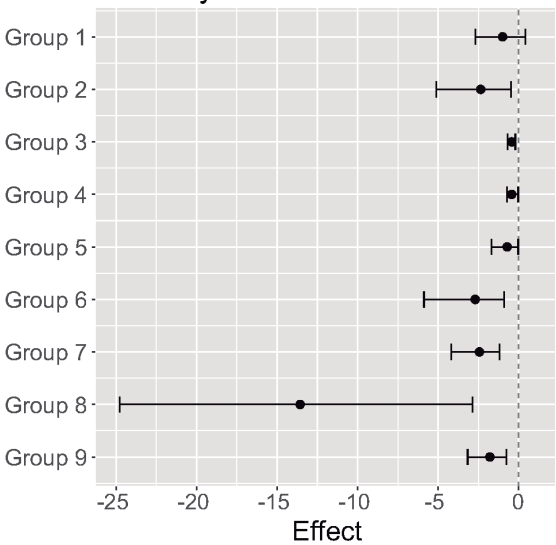

A
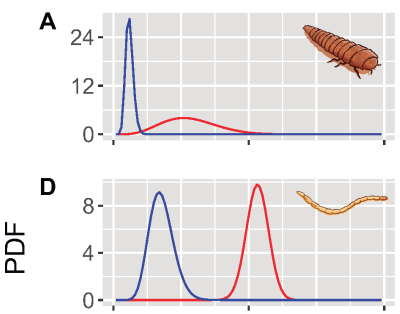

G

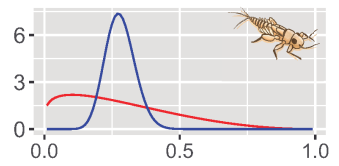

B 20-

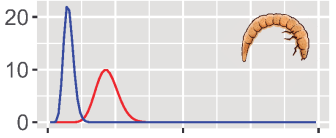

E
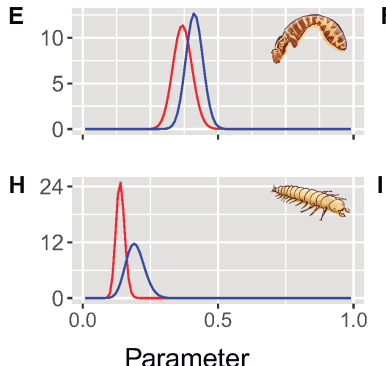

Parameter c

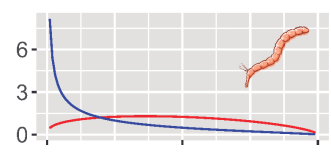

$F$
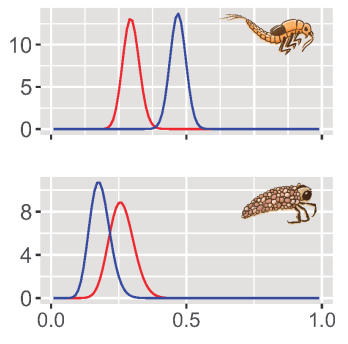

A 0
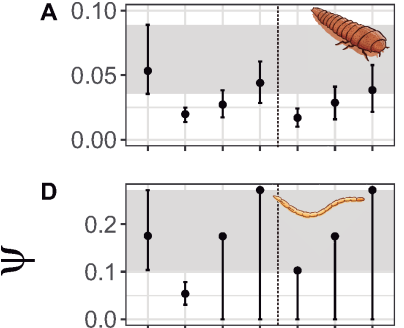

G

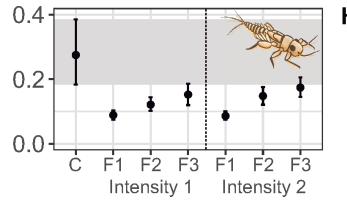

B

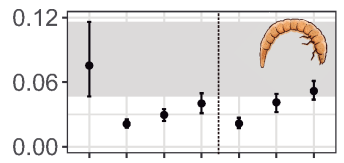

E

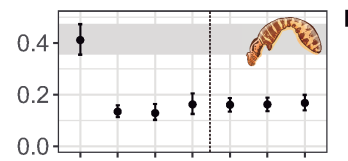

H

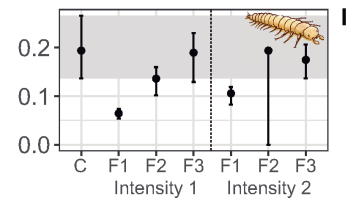

C

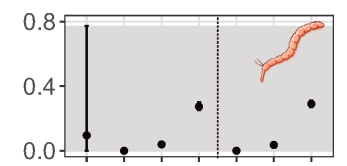

$F$
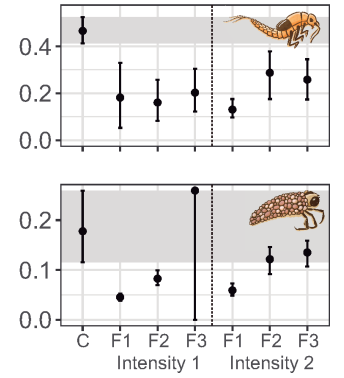